\title{
Temperature and rainfall anomalies in Africa predict timing of spring migration in trans-Saharan migratory birds
}

\author{
Nicola Saino ${ }^{1, *}$, Diego Rubolini ${ }^{1}$, Niclas Jonzén ${ }^{2}$, Torbjørn Ergon ${ }^{3}$, \\ Alessandro Montemaggiori ${ }^{4}$, Nils Chr. Stenseth ${ }^{3}$, Fernando Spina ${ }^{5}$ \\ ${ }^{1}$ Dipartimento di Biologia, Università degli Studi di Milano, via Celoria 26, 20133 Milan, Italy \\ ${ }^{2}$ Department of Theoretical Ecology, Ecology Building, Lund University, 22362 Lund, Sweden \\ ${ }^{3}$ Centre for Ecological and Evolutionary Synthesis (CEES), Department of Biology, University of Oslo, PO Box 1066, \\ Blindern, 0316 Oslo, Norway \\ ${ }^{4}$ Istituto di Ecologia Applicata, Via Cremona 71, 00161 Rome, Italy \\ ${ }^{5}$ Istituto Nazionale per la Fauna Selvatica (INFS), via Ca' Fornacetta 9, 40064 Ozzano Emilia (BO), Italy
}

\begin{abstract}
The long-term advance in the timing of bird spring migration in the Northern Hemisphere is associated with global climate change. The extent to which changes in bird phenology reflect responses to weather conditions in the wintering or breeding areas, or during migration, however, remains to be elucidated. We analyse the relationships between the timing of spring migration of 9 species of trans-Saharan migratory birds across the Mediterranean, and thermal and precipitation anomalies in the main wintering areas south of the Sahara Desert and in North African stopover areas. Median migration dates were collected on the island of Capri (southern Italy) by standardized mist-netting during 1981 to 2004. High temperatures in sub-Saharan Africa (Sahel and Gulf of Guinea) prior to northward migration (February and March) were associated with advanced migration. Moreover, birds migrated earlier when winter rainfall in North Africa was more abundant. The relationships between relevant meteorological variables and timing of migration were remarkably consistent among species, suggesting a coherent response to the same extrinsic stimuli. All these results were obtained while statistically controlling for the long-term trend towards the earlier timing of spring migration across the Mediterranean that has been documented in previous analyses of the same dataset, a trend that was confirmed by the present analyses. In conclusion, our results suggest that thermal conditions in the wintering quarters, as well as rainfall in North African stopover areas, can influence interannual variation in migration phenology of trans-Saharan migratory birds, although the ecological mechanisms that causally link meteorological conditions to the timing of migration remain a matter of speculation.
\end{abstract}

KEY WORDS: Arrival date $\cdot$ Long-distance migration $\cdot$ Mediterranean $\cdot$ Sahel $\cdot$ Weather

\section{INTRODUCTION}

The phenology of bird migration in the Northern Hemisphere has shown remarkable changes during the last decades (see reviews in Møller et al. 2004, Gordo 2007, this issue, Rubolini et al. 2007a, this issue). A general pattern of advanced spring migration and arrival dates to the European breeding areas has been demonstrated for short-distance migratory species, as well as for long-distance migrants that overwinter south of the Sahara desert (Tryjanowski et al. 2002, Cotton 2003, Hüppop \& Hüppop 2003, Both et al. 2004, Gordo \& Sanz 2005, 2006, Sparks et al. 2005, Jonzén et al. 2006a, Zalakevicius et al. 2006), although excep- 
tions have also been documented (Mason 1995, Loxton \& Sparks 1999, Peñuelas et al. 2002, Gordo et al. 2005, Peintinger \& Schuster 2005). Rapid shifts in migration phenology have been paralleled by a shift in timing of phenological events of other organisms, such as leafing and flowering, or first appearance date of insects (Gordo \& Sanz 2005, Menzel et al. 2006, Schwartz et al. 2006).

The consistency of the pattern of phenological shifts across diverse animal and plant taxa and its association with warming, which has occurred during the last decades in the Northern Hemisphere (IPCC 2001), have led to the hypothesis that climatic changes are directly driving the observed trends in phenological events (Both \& Visser 2001, Parmesan \& Yohe 2003, Root et al. 2003, Ahola et al. 2004, Jonzén et al. 2006a, Schwartz et al. 2006, Gienapp et al. 2007, this issue, Gordo 2007, Rubolini et al. 2007a).

The mechanism that mediates this association may consist of a rapid evolutionary change in the populations of organisms driven by the increasing advantage of early arrival at the breeding grounds (Pulido \& Berthold 2004, Jonzén et al. 2006a, 2007, this issue, Pulido 2007, this issue; but see Both 2007), which, in turn, may arise as a consequence of phenological shifts of species (e.g. prey) that are ecologically linked to migratory birds.

Natural selection, however, is also expected to have led to the evolution of mechanisms that allow for phenotypically plastic responses to varying ecological conditions (Schlichting \& Pigliucci 1998). Individual migratory birds may thus adjust their decisions on timing of departure from the wintering grounds, migration speed and route, and timing of arrival at the breeding grounds according to contingent ecological conditions (Przybylo et al. 2000, Møller \& Merilä 2004, Gordo 2007).

Several studies that have investigated interannual variation in first or mean arrival dates at the breeding grounds in relation to ecological (mainly thermal) conditions at destination upon arrival or along the migration route have demonstrated that in years with relatively high spring temperatures migrants arrive earlier (Huin \& Sparks 1998, 2000, Loxton et al. 1998, Sokolov et al. 1998, Sparks \& Mason 2001, Tryjanowski et al. 2002, Croxton et al. 2006, Gordo \& Sanz 2006, Rubolini et al. 2007b, Sparks \& Tryjanowski 2007, this issue). Whatever the mechanisms that allow birds to tune their arrival schedule based on current conditions 100s or 1000s of kilometres ahead, these studies suggest that birds can balance the ecological or socio-sexual costs and benefits of early departure from the wintering areas and arrival at the breeding grounds.

The analysis of the covariation between arrival dates and conditions at destination is made relatively easy by the obvious association between the phenological datum and the area, and thus the ecological conditions to which it refers. Conversely, the analysis of the covariation between arrival or migration dates and conditions in the wintering grounds or en route is hampered by the only superficial knowledge of the spatiotemporal distribution of most migratory species during migration or wintering (Gordo 2007). In a few instances where the wintering areas of a specific breeding population could be identified with reasonable accuracy, variation in ecological conditions during wintering or migration have been shown to result in phenotypic adjustment of the individuals' phenology (e.g. Saino et al. 2004). In other studies, the problem of fuzziness in the identification of wintering areas has been circumvented by analysing the statistical effect of winter conditions in Africa at wide, sub-continental scales (Cotton 2003, Gordo et al. 2005, Rodríguez-Teijeiro et al. 2005, Gordo \& Sanz 2006).

In the present study, we analyse the relationships between the median spring migration dates of 9 species of long-distance passerine migrants in southern Italy (island of Capri, Tyrrhenian Sea) and weather conditions at the African wintering/staging grounds. Most of these species breed mainly in Europe, overwinter in the Sahel or south of it, and migrate through southern Europe in April/May (Cramp 1998). Those populations that winter farther south in Africa, however, may stopover in the Sahel during late winter to early spring (Moreau 1972, Morel \& Morel 1992, Pilastro \& Spina 1997). During spring stopover in the Sahel region, migratory passerines are known to feed on invertebrates but chiefly on a variety of berries (Moreau 1972, Morel 1973, Morel \& Morel 1992, Stoate \& Moreby 1995). However, from March onwards, ecological conditions deteriorate because of the advancement of the dry season and a marked increase of temperatures (Morel 1973, Morel \& Morel 1992). Therefore, thermal conditions in the Sahel in February and March, just before the bulk of migratory movements, may influence the timing of departure of long-distance European migrants because they can affect body condition either directly (e.g. by reducing energy requirements for fattening; Morel 1973), or via an effect on resource availability. Similarly, the amount of Sahel rainfall during the previous year's wet season (June to October), which is known to profoundly influence population dynamics of trans-Saharan migrants (e.g. Peach et al. 1991, Baillie \& Peach 1992, Szép 1995), may affect ecological conditions and the timing of departure of migrants from the wintering grounds (e.g. Saino et al. 2004). Thus, we analysed migration dates in relation to temperature in winter to early spring in an African area comprising the Sahel and a region south of it and north of $3^{\circ} \mathrm{N}$ (hereafter 'Sahel' for sim- 
plicity), and in relation to the wet season rainfall of the previous year in the Sahel.

Long-distance spring migrants that fly across the Tyrrhenian Sea depart from the coasts of eastern Algeria, Tunisia and the western Gulf of Sirte to cross the southern central Mediterranean (Pilastro \& Spina 1997, Spina et al. 2006). To test for an effect of conditions that migrants encounter en route, we considered temperature and rainfall data from a North African region centred on Tunisia. We used the February to April mean temperature anomalies for Tunisia, because we assume that temperatures in these passage areas do not directly modulate the timing of migration, but rather that general temperature conditions prior to, and during, passage could influence habitat quality for stopover migrants. For precipitation, we considered the Sahel rainfall index (Janowiak 1988) and the mean November to April rainfall anomalies for North Africa. In fact, most rainfall in Tunisia occurs during late autumn to early winter (Wellens 1997), and we speculated that this amount of rainfall can directly affect vegetation and animals (e.g. prey), and thus habitat quality for transient migrants, up to several months later.
The species considered in the present study were 9 common long-distance passerine migrants breeding in Eurasia and wintering in sub-Saharan Africa (see Table 1) (Cramp 1998). All species therefore winter or migrate through the Sahel region before crossing the Sahara Desert and the Mediterranean. The number of yearly captures ranged from 14 to 1153 ind. per species, for a total of 47352 ind. No data were available for the tree pipit Anthus trivialis in 1981.

\subsection{Estimating median migration dates}

Since the proportion of migrants arriving outside the April 17 to May 15 period may vary from year to year, empirical percentiles from ringing dates may be biased, and may underestimate the variation in measures of the migration distribution. We therefore fitted a Gaussian seasonal distribution curve in a Poisson regression on the daily numbers of trapped birds and used the distribution derived from this analysis to estimate median arrival date of the yearly migratory distributions of each species.

\section{METHODS}

\subsection{Study site and species}

Migratory birds were captured on the island of Capri $\left(40^{\circ} 33^{\prime} \mathrm{N}, 14^{\circ} 15^{\prime} \mathrm{E}\right)$ (Fig. 1) in the period from 1981 to 2004 (except 1982 to 1985, and 2000) by means of standardized mist-netting (see Jonzén et al. 2006a,b for details). In order to homogenize the trapping effort across years, the data included in this study were restricted to the period April 17 to May 15, which corresponds to the peak migratory period of most trans-Saharan migrants across the central Mediterranean (Spina et al. 1993, Rubolini et al. 2005), when trapping occurred in all years. During spring, long-distance migratory birds stopover at Capri to rest, mainly for a short time (Holmgren \& Engström 2006), after the crossing of the Sahara desert and of the Mediterranean Sea (Spina et al. 2006). The trapping area consists of ca. 2 ha of dry and bushy vegetation (garrigue and macchia). Trapping activities were carried out every day (from dawn to dusk), except in cases of heavy wind or rain (see Jonzén et al. 2006a for details).

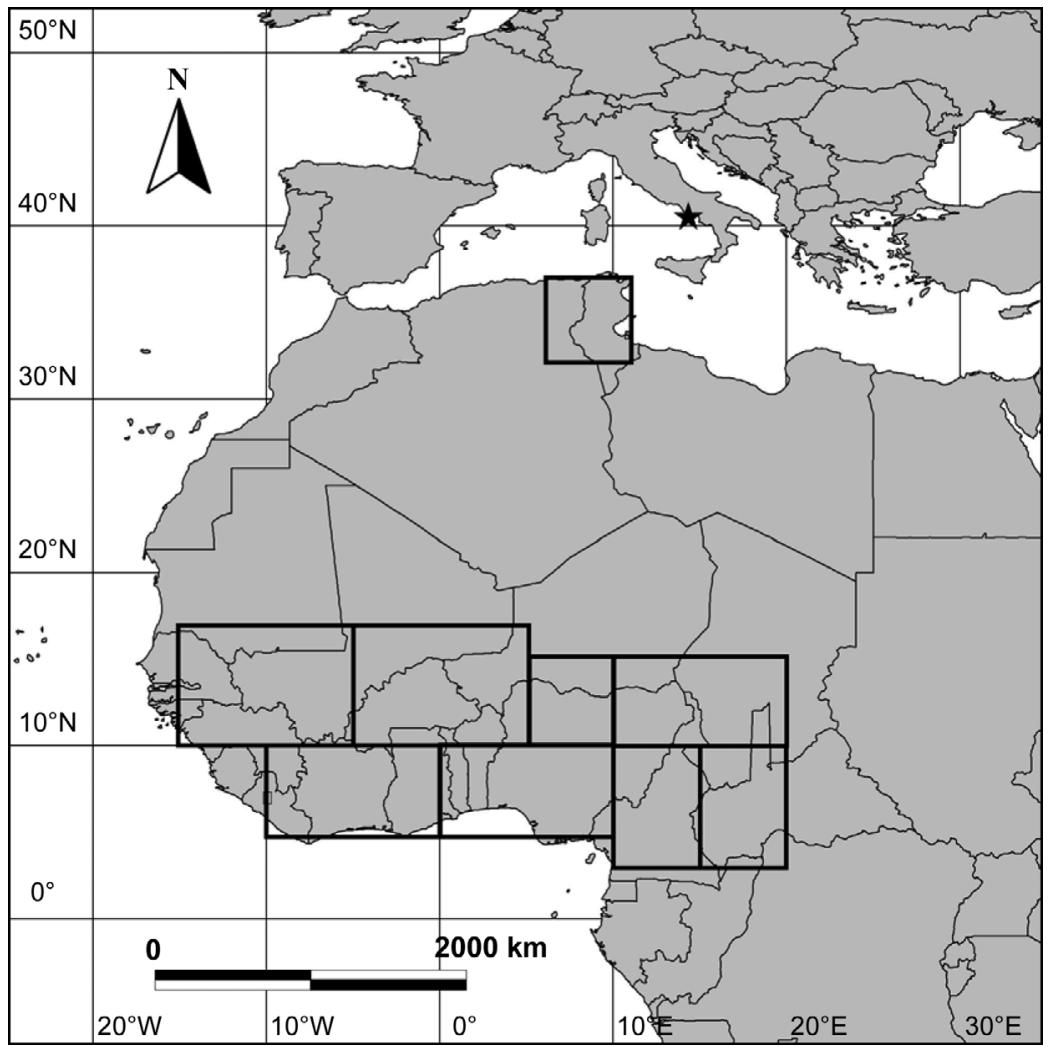

Fig. 1. Map of Africa and southern Europe showing the 8 Sahel regions (from W to E, upper row: Guinea, Burkina Faso, Niger, Chad; lower row: Ivory Coast, Nigeria, Cameroon, Central African Republic). The Tunisia region in North Africa and Capri (star) where migrants were captured are also shown 
To account for large extra-Poisson variation in the data due to the huge day-to-day variation in the number of trapped birds, we used Bayesian Markov chain Monte Carlo (MCMC) methods, as implemented in the software WinBUGS 1.4 (Spiegelhalter et al. 2003).

A Gaussian seasonal distribution curve can be fitted as a quadratic function on a logarithmic scale [log (expected number on Day $\left.\left.x_{i}\right)=\mu_{i}=\beta_{0}+\beta_{1} x_{i}+\beta_{2} x_{i}^{2}\right]$. However, the following re-parameterisation gave lower autocorrelations in the MCMC simulations: 'mean' = $\tau=-\beta_{1} /\left(2 \beta_{2}\right)$, 'peak' $=\rho=\beta_{0}+\beta_{1} \tau+\beta_{2} \tau^{2}$, and 'standard deviation' $=\kappa=1 / \sqrt{-2 \beta_{2}}$. Two alternative models were considered for modelling the over-dispersion in the data, either a log-normal component of the Poisson parameter $\left[\log \left(\lambda_{i}\right)=\mu_{i}+\varepsilon_{i}\right.$, where $\left.\varepsilon_{i} \sim \mathrm{N}\left(0, \sigma^{2}\right)\right]$, or a stochastic day-effect from a Gamma distribution with the shape parameter being $1 /$ scale parameter $\left[\lambda_{i}=\mathrm{e}^{\mu_{i}} v_{i}\right.$ where $\left.v_{i} \sim \Gamma(\alpha, 1 / \alpha), E\left(v_{i}\right)=1\right]$. In the first model, the expected number of ringed birds on Day $i$ is $\mathrm{E}\left(\lambda_{i}\right)=$ $\mathrm{e}^{\mu_{i}+\sigma^{2} / 2}$. In the latter model, the expected number is $\mathrm{E}\left(\lambda_{i}\right)=\mathrm{e}^{\mu_{i}}$. The Gamma model gave better goodness-offit statistics (details not shown) and a lower deviance information criterion value, and was hence used in the analyses. The model was fitted for each species separately, and all parameters except $\alpha$ were year specific ( $\alpha$ was constant across years). As estimates of migration dates, we used the medians of posterior distributions of the parameter $\tau$.

To facilitate numerical convergence and eliminate nonsensical parameter values from the a posteriori distributions, we constrained the parameter space by using uniform and rather vague priors for the parameters $\tau$ (mean passage date) and $\kappa$ (standard deviation in passage date). For $\kappa$ of all years and species, we used a uniform $(0.25,10)$ prior. The priors for mean ringing dates $(\tau)$ varied among species and spanned over what we considered the maximum reasonable range for that species (Table 1). The peak of the expectation curve ( $\rho)$ was allowed to vary between 0 and 10 times the maximum observed daily count of the species, which is an almost uninformative prior. The prior of the parameter in the Gamma term accounting for over-dispersion, $\alpha$, was set to an uninformative $\Gamma($ scale $=1 / 1000$, shape $=$ 1000) distribution.

We used relatively long chains in the MCMC simulations due to persistent long-lagged autocorrelations in some parameters (6 parallel chains of 80000 iterations with an initial burn-in period of 10000 iterations and thereafter sampling at every 5 th iteration). Convergence was confirmed by the Gelman and Rubin statistic (Gelman 1996).

Goodness-of-fit was assessed by using Bayesian pvalues (Gelman et al. 1995). An acceptable fit was verified with respect to deviance, skewness and kurtosis of deviance residuals, correlation between deviance residuals and day of the year $\left(x_{i}\right)$, and correlation between the deviance residuals and the fitted expectations $\mathrm{e}^{\mu_{i}}$.

\subsection{Weather data}

African temperature and rainfall anomalies (TA and RA, respectively) were obtained from the NOAA Satellite and Information Service of the U.S. Department of Commerce (GHCN Land Surface Data, www.ncdc. noaa.gov/gcag/gcag.html). Anomalies are expressed as the deviation from the 1961 to 1990 mean value. We obtained monthly (February and March) TA for 8 regions of sub-Saharan Africa, located between $3^{\circ}$ to $17^{\circ} \mathrm{N}$ and $15^{\circ} \mathrm{W}$ to $20^{\circ} \mathrm{E}$ (Fig. 1). Regions were identified by the name of 1 country encompassing each area (Fig. 1). Four of these regions (Guinea, Burkina Faso, Niger, Chad) are mostly within the 'true' Sahel region, whereas the other 4 are in adjacent areas with tropical climate (Morel \& Morel 1992).

Table 1. Priors for mean passage dates on Capri. The parameters $\tau$ were constrained to fall within the intervals indicated for each species by using a uniform prior value. The range of estimated values of $\tau$ (based on the medians of the posterior distributions over all years) are shown to the right (see Section 2.2 and Jonzén et al. 2006a)

\begin{tabular}{|c|c|c|c|c|}
\hline Taxon & Common name & $\begin{array}{l}\text { Earliest allowed } \\
\text { mean date }\end{array}$ & $\begin{array}{l}\text { Latest allowed } \\
\text { mean date }\end{array}$ & $\begin{array}{l}\text { Range in estimated } \\
\text { median date }\end{array}$ \\
\hline Sylvia borin & Garden warbler & Apr 15 & May 30 & May 8 to May 17 \\
\hline Hippolais icterina & Icterine warbler & Apr 25 & May 25 & May 7 to May 21 \\
\hline Ficedula hypoleuca & Pied flycatcher & Apr 15 & May 20 & Apr 19 to May 2 \\
\hline Phoenicurus phoenicurus & Redstart & Mar 10 & May 15 & Apr 24 to May 6 \\
\hline Muscicapa striata & Spotted flycatcher & Apr 20 & May 25 & May 3 to May 18 \\
\hline Anthus trivialis & Tree pipit & Mar 25 & May 10 & Apr 21 to May 6 \\
\hline Saxicola rubetra & Whinchat & Apr 5 & May 20 & Apr 23 to May 11 \\
\hline Sylvia communis & Whitethroat & Mar 25 & May 25 & Apr 29 to May 14 \\
\hline Phylloscopus trochilus & Willow warbler & Mar 15 & May 15 & Apr 20 to May 3 \\
\hline
\end{tabular}


As an indication of the amount of rainfall in the Sahel, which could be an indicator of habitat quality for migratory birds (Møller 1989, Peach et al. 1991, Szép 1995), we used the Sahel wet season rainfall index (RI) (June to October) of the year preceding the arrival of migrants to Capri (jisao.washington.edu/ data_sets/sahel).

We also obtained TA and RA for the area of North Africa that is crossed by birds before landing at Capri, broadly defined as Tunisia (Fig. 1; extreme coordinates, $32^{\circ}$ to $37^{\circ} \mathrm{N}$ and $6^{\circ}$ to $11^{\circ} \mathrm{E}$ ). RA were calculated as the mean values from November of the preceding year to April of the year of arrival at Capri.

\subsection{Statistical analyses}

In order to reduce the number of meteorological variables, we subjected TA for the 8 Sahel regions to principal component analyses (PCA) based on correlation matrices for February and March separately, including TA for the $19 \mathrm{yr}$ that had phenological information from Capri. However, PCA for the tree pipit was based on $18 \mathrm{yr}$, as phenological data from 1981 were not available (see Section 2.1). To analyse the effect of weather variables on median timing of spring migration for each species, we ran multiple regression analyses, where the principal components (PCs) of the Sahel temperature were included as predictors. Year was always included to control for any long-term temporal trend in the timing of spring migration (Jonzén et al. 2006a). Other weather variables (i.e. Tunisia TA, Sahel RI and Tunisia RA) were added separately to models containing year and PCs to test for concomitant additional effects of weather conditions along the migration route (Tunisia anomalies) or winter ecological conditions in the passage areas (Sahel rainfall).

The relationships between median timing of spring migration at Capri and weather conditions were analysed across all species, by calculating the mean slopes for each predictor included in the multiple regression models for each species. We then calculated the $95 \% \mathrm{CI}$ of these effects based on the sampling variance of each of the estimated slopes (i.e. considering the set of species as given, and not a random sample; see formula in Table 4), and the significance of the relationships was evaluated by checking whether estimated confidence intervals included 0 . The strength of the effects of weather variables across all species for a given set of models was expressed as the mean of $\mathrm{Zr}$ transformed standardized regression coefficients of each species and variable (Rosenthal 1991). No significant temporal autocorrelation in median migration dates emerged for all species at Box-Ljung tests (details not shown).

\section{RESULTS}

\subsection{Correlations among temperature and rainfall in the Sahel and Tunisia}

TA in February or March for the 8 sub-Saharan regions were subjected to separate PCA. Both analyses extracted 2 PCs with an associated eigenvalue $>1$, which collectively explained $>90 \%$ of the variance; these were used in subsequent analyses. The factor loadings for February indicated that PC1 was a vector of increasing TA, mainly in the 6 easternmost regions, while PC 2 was mainly a vector of increasing TA in western Guinea and the Ivory Coast (Table 2). The analysis on TA in March led to similar results, with the exception that TA for Burkina Faso also had a high loading on PC2 (Table 2). Overall, these analyses suggest that the pattern of variation in TA in western 'Sahel' during late winter varied along a west to east axis.

The PC1 for February was negatively correlated with the Sahel RI ( $\mathrm{r}=-0.50, \mathrm{n}=19, \mathrm{p}=0.031)$ and positively correlated with TA $(r=0.65, \mathrm{n}=19, \mathrm{p}=0.002)$, but not with RA in Tunisia $(r=-0.21, n=19, p=0.38)$. A significant positive correlation existed also between PC2 in March and TA in Tunisia ( $\mathrm{r}=0.67, \mathrm{n}=19, \mathrm{p}=0.002)$. The correlations between the PCs and Sahel RI and TA or RA in Tunisia were far from statistical significance in all the other cases (unsigned $\mathrm{r}<0.36, \mathrm{n}=19$, $\mathrm{p}>0.13$ ).

TA in the Sahel did not show any significant temporal trend of variation during the study years (regression of PC1 or PC2 for February or March on year was always nonsignificant; $\mathrm{p}>0.05)$. TA in Tunisia increased significantly by $0.11^{\circ} \mathrm{C}(0.02 \mathrm{SE})$ per year $\left(t_{17}=5.14, \mathrm{p}<0.001\right)$. The Sahel RI increased by 0.062 units $(0.023 \mathrm{SE})$ per year $\left(t_{17}=2.66, \mathrm{p}=0.017\right)$, whereas no significant temporal variation existed in Tunisia RA $\left(t_{17}=0.64, \mathrm{p}=0.53\right)$.

Table 2. Principal component loadings of February or March temperature anomalies (TA) computed over the 19 study yr (see Section 2.4) for 8 sub-Saharan regions (see Fig. 1). The percentage of variance explained by each component is given in parentheses. The principal component analysis (PCA) of TA during the $18 \mathrm{yr}$ when the tree pipit Anthus trivialis was studied (see Section 2.1) gave strictly similar results and is not reported for brevity

\begin{tabular}{|lcrrr|}
\hline \multirow{2}{*}{ Region } & \multicolumn{2}{c}{ Feb } & \multicolumn{2}{c|}{ Mar } \\
& PC1 & PC2 & PC1 & PC2 \\
& $(66.5)$ & $(24.8)$ & $(57.7)$ & $(32.3)$ \\
\hline Guinea & & & & \\
Burkina Faso & 0.29 & 0.86 & -0.19 & 0.89 \\
Niger & 0.82 & 0.47 & 0.63 & 0.72 \\
Chad & 0.97 & -0.17 & 0.96 & -0.18 \\
Ivory Coast & 0.92 & -0.34 & 0.90 & -0.40 \\
Nigeria & 0.64 & 0.72 & 0.37 & 0.90 \\
Cameroon & 0.94 & 0.12 & 0.90 & 0.37 \\
Central African Republic & 0.90 & -0.40 & 0.91 & -0.35 \\
& 0.83 & -0.44 & 0.83 & -0.11 \\
\hline
\end{tabular}




\subsection{Median migration dates in relation to temperature and rainfall anomalies}

We first computed simple correlation coefficients between year or meteorological variables and migration date for each species. Mean Fisher z-transformed correlation coefficients (Zr) computed across species were significantly $<0$ for year, PC1 and PC2 from March TA in Sahel, and TA and RA in Tunisia (Table 3).

Because the primary focus of the present study was on the relationship between migration timing and temperature in the Sahel, we initially ran multiple regression analyses of median migration date of the 9 species with year and PC1 and PC2 scores of TA for February or March as independent variables. Mean partial regression coefficients computed across the 9 species were significantly negative for PC1 in both months and PC2 in February (Model 1 in Table 4). The sign of partial regression coefficients for the PCs (Table 4) in combination with that of factor loadings (Table 2) indicates that migration occurred earlier when March temperatures in the Sahel were high; in addition, it

Table 3. Mean Zr-values, 95\% confidence limits (CL) from simple correlation analyses of median migration date and meteorological variables. ${ }^{*} 95 \%$ CL excluded 0

\begin{tabular}{|lrl|}
\hline Variable & Zr & \multicolumn{1}{c|}{$95 \%$ CL } \\
\hline Year & -0.45 & -0.59 to $-0.30^{*}$ \\
PC1 Feb Sahel TA & -0.17 & -0.37 to 0.02 \\
PC2 Feb Sahel TA & 0.09 & -0.06 to 0.23 \\
PC1 Mar Sahel TA & -0.33 & -0.44 to $-0.22^{*}$ \\
PC2 Mar Sahel TA & -0.18 & -0.34 to $-0.02^{*}$ \\
Tunisia TA (Feb-Apr) & -0.22 & -0.33 to $-0.11^{*}$ \\
Sahel RI & -0.18 & -0.41 to 0.05 \\
Tunisia RA (Nov-Apr) & -0.38 & -0.53 to $-0.23^{*}$ \\
\hline
\end{tabular}

occurred earlier when February temperatures in the western Sahel were high compared to those in the eastern Sahel, as indicated by the sign of the loadings on PC2, which were positive for western and negative for eastern Sahel regions (see Table 2). In these models, the mean partial regression coefficient for the effect of year was also significantly $<0$, implying a general advancement of migration date in recent years (Jonzén et al. 2006a) (Table 4).

The effects of Sahel RI and RA/TA in Tunisia on median migration dates were tested by adding these terms to Model 1 in Table 4. Each additional term was tested in separate models to reduce the risk of overparameterisation. The mean of the regression coefficients of March PC1 and February PC2 was significantly $<0$ in all 3 additional sets of analyses, whereas the mean regression coefficient for February PC1 became nonsignificantly different from 0 .

The mean regression coefficients of the Sahel RI and TA in Tunisia were nonsignificantly different from 0 (Table 4; Models 2 and 3), whereas the mean regression coefficient of the RA in Tunisia was $<0$ (Table 4; Model 4), indicating that migration was advanced in springs that were preceded by autumns and winters with relatively large precipitation. In Models 2 to 4 (Table 4), year retained its significantly negative mean effect, as in Model 1.

The sign of the partial regression coefficients of migration date on the PC1 of March TA and that of RA in Tunisia was negative for all the species considered, and this was the case also for February PC2, with the exception of the spotted flycatcher Muscicapa striata (Table 5).

To test for a differential effect of temperature and rainfall data in Africa on the 9 species we ran an analysis of covariance in which we initially included species, year and meteorological variables. None of the interac-

Table 4. Mean partial regression coefficients (Slope), $95 \%$ confidence limits (CL) of median migration date and mean Zr reflecting effect size computed across the 9 species from multiple regression models including year, PCs of February and March temperature anomalies (TA), and Tunisia TA or Sahel rainfall index (RI) or Tunisia rainfall anomalies (RA). Confidence interval is based on the sampling variance of each of the estimated slopes (i.e. considering the set of species as given, and not a random sample). Variance of the mean equals $(1 / 9)^{2} \sum_{i=1}^{9} V_{i}$, where $V_{i}$ is the sampling variance of the slope estimate for species $i$ (separate regressions for each species). Mean regression coefficients in bold print significantly differ from 0

\begin{tabular}{|c|c|c|c|c|c|c|c|c|c|c|c|c|}
\hline \multirow[t]{2}{*}{ Variable } & \multicolumn{3}{|c|}{ Fits to Model 1} & \multicolumn{3}{|c|}{ Fits to Model 2} & \multicolumn{3}{|c|}{ Fits to Model 3} & \multicolumn{3}{|c|}{ Fits to Model 4} \\
\hline & Slope & $95 \% \mathrm{CL}$ & $\mathrm{Zr}$ & Slope & $95 \% \mathrm{CL}$ & $\mathrm{Zr}$ & Slope & $95 \% \mathrm{CL}$ & $\mathrm{Zr}$ & Slope & $95 \%$ CL & $\mathrm{Zr}$ \\
\hline Year & -0.25 & -0.35 to -0.14 & -0.44 & -0.33 & -0.50 to -0.17 & -0.66 & -0.24 & -0.37 to -0.11 & -0.44 & -0.18 & -0.29 to -0.07 & -0.32 \\
\hline PC1 Feb Sahel TA & -0.60 & -1.18 to -0.01 & -0.14 & -0.44 & -1.08 to 0.21 & -0.10 & -0.66 & -1.36 to 0.03 & 0.15 & 0.50 & -0.32 to 1.32 & 0.16 \\
\hline PC2 Feb Sahel TA & -0.94 & -1.71 to -0.16 & -0.26 & -0.94 & -1.73 to -0.15 & -0.26 & -0.93 & -1.71 to -0.16 & -0.26 & -1.30 & -2.07 to -0.52 & -0.36 \\
\hline PC1 Mar Sahel TA & -1.44 & -2.23 to -0.64 & -0.38 & -1.36 & -2.18 to -0.53 & -0.35 & -1.42 & -2.22 to -0.62 & -0.37 & -1.61 & -2.38 to -0.83 & -0.43 \\
\hline PC2 Mar Sahel TA & 0.06 & -0.59 to 0.70 & 0.02 & -0.32 & -1.15 to 0.52 & -0.08 & 0.05 & -0.61 to 0.71 & 0.02 & -0.15 & -0.79 to 0.48 & -0.03 \\
\hline Tunisia TA Feb-Apr & & - & & 1.02 & -0.39 to 2.44 & 0.25 & & - & & & - & \\
\hline Sahel RI & & - & & & - & & -0.21 & -1.34 to 0.92 & -0.02 & & - & \\
\hline Tunisia RA Nov-Apr & & - & & & - & & & - & & -0.14 & -0.21 to -0.06 & -0.42 \\
\hline
\end{tabular}


Table 5. Estimates (SE) of multiple regression coefficients for each species (taxonomic names in Table 1) from Model 4 of Table 4 (first row of each cell) and Zr-transformed partial regression coefficients (second row of each cell) reflecting effect size.

TA: temperature anomalies; RA: rainfall anomalies. Statistically significant coefficients are indicated in bold print

\begin{tabular}{|c|c|c|c|c|c|c|c|}
\hline \multirow[b]{2}{*}{ Species } & \multirow[t]{2}{*}{ Year } & \multirow[b]{2}{*}{ PC1 Feb } & \multicolumn{2}{|c|}{ Sahel TA - } & \multirow[b]{2}{*}{ PC2 Mar } & \multirow[t]{2}{*}{ Tunisia RA } & \multirow[t]{2}{*}{ Multiple $\mathrm{R}^{2}$} \\
\hline & & & PC2 Feb & PC1 Mar & & & \\
\hline Garden warbler & $\begin{array}{c}-0.22(0.15) \\
-0.44\end{array}$ & $\begin{array}{c}0.17(1.12) \\
0.05\end{array}$ & $\begin{array}{c}-0.78(1.06) \\
-0.23\end{array}$ & $\begin{array}{c}-1.18(1.07) \\
-0.36\end{array}$ & $\begin{array}{c}-0.46(0.86) \\
-0.14\end{array}$ & $\begin{array}{c}-0.07(0.10) \\
-0.24\end{array}$ & 0.43 \\
\hline Icterine warbler & $\begin{array}{c}-0.36(0.20) \\
-0.59\end{array}$ & $\begin{array}{c}-0.60(1.53) \\
-0.14\end{array}$ & $\begin{array}{c}-0.69(1.46) \\
-0.16\end{array}$ & $\begin{array}{c}-0.58(1.46) \\
-0.14\end{array}$ & $\begin{array}{c}0.32(1.18) \\
0.07\end{array}$ & $\begin{array}{c}-0.05(0.14) \\
-0.12\end{array}$ & 0.33 \\
\hline Pied flycatcher & $\begin{array}{c}-0.24(0.14) \\
-0.42\end{array}$ & $\begin{array}{c}0.28(1.04) \\
0.07\end{array}$ & $\begin{array}{c}-2.00(0.99) \\
-0.57\end{array}$ & $\begin{array}{c}-1.00(1.00) \\
-0.26\end{array}$ & $\begin{array}{c}0.24(0.80) \\
0.06\end{array}$ & $\begin{array}{c}-\mathbf{0 . 2 3}(0.09) \\
-0.77\end{array}$ & 0.62 \\
\hline Redstart & $\begin{array}{c}-0.16(0.13) \\
-0.28\end{array}$ & $\begin{array}{c}2.82(0.97) \\
0.97\end{array}$ & $\begin{array}{c}-1.08(0.92) \\
-0.29\end{array}$ & $\begin{array}{c}-1.74(0.93) \\
-0.50\end{array}$ & $\begin{array}{c}1.39(0.75) \\
0.39\end{array}$ & $\begin{array}{c}-\mathbf{0 . 2 3}(0.09) \\
-0.80\end{array}$ & 0.65 \\
\hline Spotted flycatcher & $\begin{array}{c}0.17(0.19) \\
0.23\end{array}$ & $\begin{array}{c}0.00(1.47) \\
0.00\end{array}$ & $\begin{array}{c}0.05(1.40) \\
0.01\end{array}$ & $\begin{array}{c}-2.26(1.41) \\
-0.52\end{array}$ & $\begin{array}{c}\mathbf{- 2 . 5 4}(1.13) \\
-0.61\end{array}$ & $\begin{array}{c}-0.07(0.13) \\
-0.17\end{array}$ & 0.48 \\
\hline Tree pipit & $\begin{array}{c}0.00(0.22) \\
0.01\end{array}$ & $\begin{array}{c}0.03(1.38) \\
0.01\end{array}$ & $\begin{array}{c}-\mathbf{2 . 7 9}(1.23) \\
-0.95\end{array}$ & $\begin{array}{c}-2.19(1.23) \\
-0.66\end{array}$ & $\begin{array}{c}-0.48(1.10) \\
-0.13\end{array}$ & $\begin{array}{c}-0.12(0.12) \\
-0.37\end{array}$ & 0.43 \\
\hline Whinchat & $\begin{array}{c}-0.27(0.17) \\
-0.36\end{array}$ & $\begin{array}{c}0.54(1.33) \\
0.11\end{array}$ & $\begin{array}{c}-2.13(1.27) \\
-0.47\end{array}$ & $\begin{array}{c}-2.30(1.27) \\
-0.51\end{array}$ & $\begin{array}{c}-0.13(1.03) \\
-0.03\end{array}$ & $\begin{array}{c}-0.25(0.12) \\
-0.64\end{array}$ & 0.60 \\
\hline Whitethroat & $\begin{array}{c}-0.25(0.15) \\
-0.41\end{array}$ & $\begin{array}{c}-0.20(1.18) \\
-0.05\end{array}$ & $\begin{array}{c}-1.18(1.12) \\
-0.30\end{array}$ & $\begin{array}{c}-2.01(1.13) \\
-0.54\end{array}$ & $\begin{array}{c}-0.16(0.91) \\
-0.04\end{array}$ & $\begin{array}{c}-0.12(0.11) \\
-0.34\end{array}$ & 0.56 \\
\hline Willow warbler & $\begin{array}{c}-0.30(0.15) \\
-0.59\end{array}$ & $\begin{array}{c}1.46(1.15) \\
0.43\end{array}$ & $\begin{array}{c}-1.08(1.10) \\
-0.31\end{array}$ & $\begin{array}{c}-1.22(1.10) \\
-0.35\end{array}$ & $\begin{array}{c}0.44(0.89) \\
0.12\end{array}$ & $\begin{array}{c}-0.09(0.10) \\
-0.29\end{array}$ & 0.46 \\
\hline
\end{tabular}

tion terms significantly predicted variation in migration date, implying that the effect of year and meteorological conditions on migration date did not vary among species (Table 6). The simplified model includ- ing only main effects showed significant negative effects of February PC2 and March PC1 of TA in the Sahel, and of RA in Tunisia (Table 6), consistent with the analyses presented in Table 4 .

Table 6. Analysis of variance of median migration date of the 9 species over 19 study years (18 yr for the tree pipit Anthus trivialis) in relation to year and meteorological data in the Sahel and Tunisia. The interactions between species and year or meteorological variables were invariably nonsignificant and were therefore excluded from the model on the right side of the table. Degrees of freedom of factor and covariates were the same for the 3 models. The model with interactions explained $88 \%$ of the total variance, while the other 2 explained $82 \%$ of the total variance. Partial eta-squared $\left(\eta_{p}^{2}\right)$ is a measure of effect size that is defined as the proportion of the effect plus the error variance that is attributable to the effect. TA: temperature anomalies; RA: rainfall anomalies; RI: rainfall index

\begin{tabular}{|c|c|c|c|c|c|c|c|c|c|c|}
\hline & \multicolumn{3}{|c|}{ Model with interactions } & \multicolumn{3}{|c|}{ Model without interactions } & \multicolumn{3}{|c|}{ Step-down model } & \multirow{2}{*}{$\eta_{p}^{2}$} \\
\hline & $\mathrm{df}$ & $F$ & $\mathrm{p}$ & $F$ & $\mathrm{p}$ & $\eta_{\mathrm{p}}^{2}$ & $F$ & $\mathrm{p}$ & Coefficient (SE) & \\
\hline Species & 8 & 0.57 & 0.80 & 78.32 & 0.001 & 0.80 & 79.43 & 0.001 & & 0.80 \\
\hline PC1 Feb Sahel TA & 1 & 0.92 & 0.34 & 1.03 & 0.31 & 0.01 & & & & \\
\hline PC2 Feb Sahel TA & 1 & 9.60 & 0.003 & 10.72 & 0.001 & 0.07 & 10.14 & 0.002 & $-1.16(0.37)$ & 0.06 \\
\hline PC1 Mar Sahel TA & 1 & 13.73 & 0.001 & 15.49 & 0.001 & 0.09 & 15.89 & 0.001 & $-1.47(0.37)$ & 0.09 \\
\hline PC2 Mar Sahel TA & 1 & 0.44 & 0.51 & 0.50 & 0.48 & 0.00 & & & & \\
\hline Tunisia RA (Nov-Apr) & 1 & 9.72 & 0.002 & 11.13 & 0.001 & 0.07 & 16.62 & 0.001 & $-0.10(0.03)$ & 0.10 \\
\hline Species $\times$ Year & 8 & 0.57 & 0.80 & & & & & & & \\
\hline Species $\times$ PC1 Feb Sahel TA & 8 & 0.67 & 0.72 & & & & & & & \\
\hline Species $\times$ PC2 Feb Sahel TA & 8 & 0.53 & 0.83 & & & & & & & \\
\hline Species $\times$ PC1 Mar Sahel TA & 8 & 0.24 & 0.98 & & & & & & & \\
\hline Species $\times$ PC2 Mar Sahel TA & 8 & 0.80 & 0.60 & & & & & & & \\
\hline Model with interactions & 89 & & & & & & & & & \\
\hline Model without interactions & 153 & & & & & & & & & \\
\hline Step-down model & 157 & & & & & & & & & \\
\hline
\end{tabular}


When the model excluding the interactions (Table 6) was further simplified by step-down removal of nonsignificant covariates, the effect sizes of PCs of Sahel TA remained virtually unchanged, whereas the effect size associated with RA in Tunisia and that associated with year markedly increased (Table 6).

\section{DISCUSSION}

The timing of spring migration at a Mediterranean island in 9 European passerine species that winter south of the Sahara was predicted by TA during the pre-migratory period in sub-Saharan wintering/staging regions and by RA during winter and spring in North African areas, where migrants pass before crossing the Mediterranean. Median migration date was anticipated when TA in the Sahel and RA in North Africa were high. The long-term trend towards earlier migration across the Mediterranean (see also Jonzén et al. 2006a, 2007) was further confirmed by our analyses accounting for meteorological conditions during wintering or en route. These associations between meteorological variables and migration date were observed while controlling statistically for temporal trends of variation in median migration date, since the effect of year was partialled out in multiple regression and analysis of covariance models of the effect of meteorological conditions. The strength of the significant effect of TA in the Sahel or RA in Tunisia averaged across species varied from smaller than that of year (see Model 1 in Tables 4 \& 6) to larger (see Model 4 in Table 4) and, on average, was of similar magnitude to the year effect. Thus, temporal factors and meteorological conditions appeared to explain partly different components of the total variance in median migration dates.

The pattern of covariation of migration date with meteorological variables was consistent among species. Partial regression coefficients of migration dates on PC1 of March TA in the Sahel and RA in Tunisia were negative for all 9 species (Table 5), and the extent of anticipation of migration date for any given increase of temperatures in the Sahel or rainfall in Tunisia did not vary among the species. The 9 trans-Saharan migrants, therefore, appeared to react with the similar intensity to variation in ecological conditions in the wintering areas and those encountered en route.

Like the few previous studies of the relationships between phenology of migration and conditions in the wintering or stopover areas of trans-Saharan migratory birds (e.g. Cotton 2003, Saino et al. 2004, Both et al. 2005, Gordo et al. 2005, Rodríguez-Teijeiro et al. 2005, Gordo \& Sanz 2006, Jonzén et al. 2006a, Sparks \& Tryjanowski 2007), the present study is entirely corre- lational. This implies that the observed patterns of covariation between migration dates and meteorological variables in Africa cannot be assumed to reflect causation. Under the yet unverified assumption that the meteorological variables that we considered are ultimate determinants of phenological response, diverse pathways of causation can be envisaged. For instance, relatively high temperatures may act directly on physiological control of the onset of migration in the winter quarters. A perhaps more likely, alternative interpretation is that relatively high temperatures in the Sahel affect proximate ecological factors (e.g. food availability), which promote migrants' physiological conditions before migration, or reduce energy requirements associated with pre-migratory fattening (Morel 1973), thus allowing for earlier departure. An opposite, and, to our knowledge, novel perspective is that high temperatures result in a deterioration of ecological conditions, which prompt birds to depart earlier. Primary production in the Sahel is very low in late winter and further declines until late spring (Morel 1973, Morel \& Morel 1992, Philippon et al. 2005). Relatively high temperatures in early spring may further depress primary and secondary productivity in the Sahel, thus accelerating the establishment of unfavourable conditions for migrants. This implies that there would be little scope for birds to remain longer in this area, and they may thus depart even in suboptimal conditions. It may therefore be predicted that the conditions of migrants at arrival in southern Europe should be inferior in years when Sahel spring temperatures are relatively high. This hypothesis has broad implications for the interpretation of the evolutionary and ecological mechanisms that may lead to the prevailing patterns of advancement of migration dates, which have been documented for trans-Saharan migrants over longer periods than those considered in the present study. Temperatures in the Sahel since 1960 have been increasing significantly, as shown by an analysis of February and March TA (mean $\mathrm{Zr}=0.33 ; 95 \% \mathrm{CI}$ 0.15 to 0.51 ). Thus, the advancement of migration may partly result from the fact that the decline of ecological conditions for migrants wintering in the Sahel tends to start earlier, thus prompting birds to leave the wintering areas in advance. The negative effect of February $\mathrm{TA}$, as reflected by $\mathrm{PC} 2$, on migration dates may suggest that migrants start to move earlier from the westernmost parts of the Sahel when temperatures are relatively high and this results in anticipated median migration dates across the Mediterranean.

However, it should be stressed that analyses of time series of first arrival dates, rather than median migration dates as in the present study, of 7 species (only 2 of which were also included in the present study) to diverse European areas has been shown to be posi- 
tively, rather than negatively, related to TA in the Sahel (Saino \& Ambrosini 2007). This apparent discrepancy may result from species-specific variation in the effects of temperature in the Sahel on migration and arrival, regional variation in these relationships, and/or uncoupling of the phenological information content of median migration dates across a single Mediterranean isle and arrival dates of the earliest arriving individual migrants.

Positive RA in North Africa during the main rain season resulted in earlier migration in all 9 species we considered. In this case, the causal effect, if any, on migration is unlikely to be a direct one, because most of the rainfall in North Africa occurs when migrants are still south of the Sahara (Wellens 1997). Relatively rainy winters and early springs may obviously result in enhanced primary and secondary production and, proximately, in more abundant food for migrants. Migrants may simply refuel in North Africa without undergoing any significant fattening (Pilastro \& Spina 1997), and refuelling might occur more rapidly in springs following rainy winters with high primary and secondary production (by taking advantage of, e.g., nectar; Schwilch et al. 2001). In a study of the transSaharan migratory barn swallow Hirundo rustica, it has been shown that high winter NDVI (normalised difference vetatation index) in Algeria is associated with delayed arrival to the breeding areas in Denmark (Møller \& Merilä 2004). That study provided evidence of phenotypic plasticity, because changes in arrival date of the same individuals in consecutive years, rather than mean migration dates at population level were analysed. However, the 2 studies seem to point in a different direction, because we observed earlier migration after rainy winters, whereas the study of barn swallows showed a delay after winters with high NDVI, which is associated with high precipitation.

The interpretation of the present findings is also complicated by the possible spatial and temporal autocorrelation of meteorological variables at continental or intercontinental scale. TA in the Sahel and RA in Tunisia may simply be proxies, which correlate with other ecological factors that act either locally or in distant areas and cause the phenology of migration to change (see Forchhammer et al. 2002, Saino \& Ambrosini 2007). Such large-scale climate connections (e.g. Visbeck et al. 2001) may result in a correlation between meteorological conditions in different regions at different times of the year. Given the strong selection advantage of adjustment of migration schedules, migrants may have evolved to exploit environmental (e.g. temperature) cues in Africa to predict conditions months later in their breeding range, and fine-tune timing of migration accordingly, an idea which, to date, has never been tested empirically.
Studies of the putative effects of conditions in Africa on the phenology of migration of European birds are scarce. In fact, this is the first study where median migration dates have been analysed in relation to meteorological variables in sub-Saharan and Mediterranean Africa. Four previous studies have investigated the relationships between meteorological variables and first arrival dates, rather than migration dates (Cotton 2003, Gordo et al. 2005, RodríguezTeijeiro et al. 2005, Gordo \& Sanz 2006). The use of first arrival rather than mean/median migration dates as descriptors of migration phenology has diverse advantages as well as drawbacks (see Sparks et al. 2001). However, first arrival dates may be expected to respond more strongly to variation in extrinsic ecological factors, because the risks associated with anticipating arrival to the breeding grounds can be expected to be higher for individuals that arrive early (Lehikoinen et al. 2004, Rubolini et al. 2007a). The patterns of response to ecological conditions may therefore be expected to differ between these 2 aspects of the migration phenology.

Cotton (2003) found that, in England, first arrival dates of 20 migrant species had advanced with increasing temperatures in sub-Saharan Africa. In that study, correlation analyses of arrival dates and conditions during wintering were based on temperatures in Africa measured on a very large scale and did not statistically control for the effect of temporal trends in both arrival dates and conditions in Africa. Thus, it is not clear whether those associations were mediated by a concomitant effect of year on both migration phenology and conditions in Africa. Gordo et al. (2005) analysed first arrival dates of 6 migratory species in Spain in relation to temperature and precipitation in 5 broad regions encompassing all of sub-Saharan Africa. Consistent with the assumptions of the present study, they found that weather conditions in the Sahel and the coastal areas south of it had a largely prevailing effect on arrival dates. However, high temperatures in the Sahel were associated with delayed arrival of the nightingale Luscinia megarhynchos, a species not considered in our study. In addition, Gordo et al. (2005) and Gordo \& Sanz (2006) found negative effects of precipitation in the Sahel on arrival dates, whereas we failed to find an association between rainfall in the Sahel and phenology. This discrepancy could arise because of the correlation between year and Sahel rainfall index, which could have obscured a significant effect of Sahel precipitation in multiple regressions where we simultaneously accounted for long-term trends in median migration dates. However, simple correlation analyses between median migration dates of each species and Sahel rainfall failed to reveal any consis- 
tent relationship between the 2 variables (see Table 3). Similarly to the present study, Rodríguez-Teijeiro et al. (2005) showed that first arrival dates of the quail Coturnix coturnix in Spain were earlier following high temperatures during late winter to early spring in the western (but not eastern) Sahel and North Africa. Finally, Saino et al. (2004) showed that the same individual barn swallows returned earlier from migration after winters with relatively high NDVI in the Sahel and sub-Sahel region, where Italian barn swallows winter.

Thus, the few existing studies of the correlations between conditions in Africa during winter and spring migration phenology have led to different results, although differences in the specific phenological variable under scrutiny, set of species concerned, meteorological or ecological variables considered, and analytical approach strongly suggest caution in comparing these findings.

In conclusion, we showed that variation in migration phenology of 9 common species of trans-Saharan migratory birds at a Mediterranean island is related to temperature in the Sahel wintering areas and rainfall in North African passage areas. Median migration date was earlier when temperatures and precipitation were high. These effects were independent of longterm temporal trends in migration phenology, and were consistent among species. Present results therefore suggest that annual variation in migration phenology partly results from phenotypic adjustment of migration schedules driven by meteorological conditions in Africa during the wintering period, although this does not preclude that microevolutionary changes in migration phenology are occurring in trans-Saharan migrants (Jonzén et al. 2006a, 2007). In our opinion, these findings have obvious relevance to conservation of declining populations of trans-Saharan European migratory birds (e.g. Robinson et al. 2005), as they strongly suggest that migration schedules of transSaharan migrants may be influenced by meteorological conditions in the wintering and staging areas. Any differential long-term climatic change in the breeding, wintering and passage areas of these migrants may further jeopardize these declining populations by, for example, uncoupling migration phenology to ecological facts relevant to successful reproduction in Europe.

Acknowledgements. We are grateful to all the ringers involved in the study of bird migration at Capri, and to the Axel Munthe Foundation for permission to work at the Castello Barbarossa and for providing facilities during many years of fieldwork. We thank A. Lindén and 2 anonymous referees for constructive comments. Results from the Progetto Piccole Isole (INFS): Paper No. 38. This is Contribution No. 222 from Ottenby Bird Observatory.

\section{LITERATURE CITED}

Ahola M, Laaksonen T, Sippola K, Eeva T, Rainio K, Lehikoinen E (2004) Variation in climate warming along the migration route uncouples arrival and breeding dates. Glob Change Biol 10:1610-1617

Baillie SR, Peach WJ (1992) Population limitation in Palaearctic-African migrant passerines. Ibis 134(Suppl): $120-132$

Both C (2007) Comment on 'Rapid advance of spring arrival dates in long-distance migratory birds'. Science 315: $598 b$

Both C, Visser ME (2001) Adjustment to climate change is constrained by arrival date in a long-distance migrant bird. Nature 411:296-298

Both C, Artemyev AV, Blaauw B, Cowie RJ and others (2004) Large-scale geographical variation confirms that climate change causes birds to lay earlier. Proc R Soc Lond B Biol Sci 271:1657-1662

Both C, Bijlsma RG, Visser ME (2005) Climatic effects on timing of spring migration and breeding in a long-distance migrant, the pied flycatcher Ficedula hypoleuca. J Avian Biol 36:368-373

Cotton PA (2003) Avian migration phenology and global climate change. Proc Natl Acad Sci USA 100:12219-12222

Cramp S (1998) The complete birds of the western Palearctic on CD-ROM. Oxford University Press

Croxton PJ, Sparks TH, Cade M, Loxton RG (2006) Trends and temperature effects in the arrival of spring migrants in Portland (United Kingdom) 1959-2005. Acta Ornithol 41: 103-111

Forchhammer MC, Post E, Stenseth NC (2002) North Atlantic Oscillation timing of long- and short-distance migration. J Anim Ecol 71:1002-1014

Gelman A (1996) Inference and monitoring convergence. In: Gilks WR, Richardson S, Spiegelhalter DJ (eds) Markov chain Monte Carlo in practice. Chapman \& Hall, London, p 131-143

Gelman A, Carlin JB, Stern HS, Rubin DB (1995) Bayesian data analysis. Chapman \& Hall, London

Gienapp P, Leimu R, Merilä J (2007) Responses to climate change in avian migration time-microevolution versus phenotypic plasticity. Clim Res 35:25-35

Gordo O (2007) Why are bird migration dates shifting? A review of weather and climate effects on avian migratory phenology. Clim Res 35:37-58

Gordo O, Sanz JJ (2005) Phenology and climate change: a long-term study in a Mediterranean locality. Oecologia 146:484-495

Gordo O, Sanz JJ (2006) Climate change and bird phenology: a long-term study in the Iberian Peninsula. Glob Change Biol 12:1993-2004

Gordo O, Brotons L, Ferrer X, Comas P (2005) Do changes in climate patterns in wintering areas affect the timing of the spring arrival of trans-Saharan migrant birds? Glob Change Biol 11:12-21

Holmgren NMA, Engström H (2006) Stopover behaviour of spring migrating Wood Warblers Phylloscopus sibilatrix on the Island of Capri, Italy. Ornis Svec 16:34-41

Huin N, Sparks TH (1998) Arrival and progression of swallows Hirundo rustica through Britain. Bird Study 45: 361-370

Huin N, Sparks TH (2000) Spring arrival patterns of the cuckoo Cuculus canorus, nightingale Luscinia megarhynchos and spotted flycatcher Musciapa striata in Britain. Bird Study 47:22-31

Hüppop O, Hüppop K (2003) North Atlantic Oscillation and 
timing of spring migration in birds. Proc R Soc Lond B Biol Sci 270:233-240

IPCC (Intergovernmental Panel on Climate Change) (2001) Climate change 2001: the scientific basis. Cambridge University Press

Janowiak JE (1988) An investigation of interannual rainfall variability in Africa. J Clim 1:240-255

Jonzén N, Lindén A, Ergon T, Knudsen E and others (2006a) Rapid advance of spring arrival dates in long-distance migratory birds. Science 312:1959-1961

Jonzén N, Piacentini D, Andersson A, Montemaggiori A and others (2006b) The timing of spring migration in transSaharan migrants: a comparison between Ottenby, Sweden, and the island of Capri, Italy. Ornis Svec 16:27-33

Jonzén N, Lindén A, Ergon T, Knudsen E and others (2007) Response to comment on 'Rapid advance of spring arrival dates in long-distance migratory birds'. Science 315:598c

Lehikoinen E, Sparks TH, Zalakevicius M (2004) Arrival and departure dates. Adv Ecol Res 35:1-31

Loxton RG, Sparks TH (1999) Arrival of spring migrants at Portland, Skokholm, Bardsey and Calf of Man. Bardsey Obs Rep 42:105-143

Loxton RG, Sparks TH, Newnham JA (1998) Spring arrival dates of migrants in Sussex and Leicestershire (1966-1996). Sussex Bird Rep 50:182-196

Mason CF (1995) Long term trends in the arrival dates of spring migrants. Bird Study 42:182-189

Menzel A, Sparks TH, Estrella N, Koch E and others (2006) European phenological response to climate change matches the warming pattern. Glob Change Biol 12:1969-1976

Møller AP (1989) Population dynamics of a declining swallow Hirundo rustica L. population. J Anim Ecol 58:1051-1063

Møller AP, Merilä J (2004) Analysis and interpretation of long-term studies investigating responses to climate change. Adv Ecol Res 35:110-130

Møller AP, Fiedler W, Berthold P (2004) Advances in ecological research: birds and climate change. Elsevier Academic Press, Oxford

Moreau RE (1972) The Palaearctic-African bird migration systems. Academic Press, London

Morel GJ (1973) The Sahel zone as an environment for Palaearctic migrants. Ibis 115:413-417

Morel GJ, Morel MY (1992) Habitat use by Palaearctic migrants in West Africa. Ibis 134(Suppl):83-88

Parmesan C, Yohe G (2003) A globally coherent fingerprint of climate change impacts across natural systems. Nature 421:37-42

Peach W, Baillie S, Underhill L (1991) Survival of British sedge warblers Acrocephalus schoenobaenus in relation to West African rainfall. Ibis 133:300-305

Peintinger M, Schuster S (2005) Veränderungen der Erstankünfte bei häufigen Zugvogelarten in Südwestdeutschland. Vogelwarte 43:161-169

Peñuelas J, Filella I, Comas P (2002) Changed plant and animal life cycles from 1952 to 2000 in the Mediterranean region. Glob Change Biol 8:531-544

Philippon N, Mougin E, Jarlan L, Frison PL (2005) Analysis of the linkages between rainfall and land surface conditions in the West African monsoon through CMAP, ERSWSC, and NOAA-AVHRR data. J Geophys Res 110: D24115

Pilastro A, Spina F (1997) Ecological and morphological correlates of residual fat reserves in passerine migrants at their spring arrival in southern Europe. J Avian Biol 28:309-318

Przybylo R, Sheldon BC, Merilä J (2000) Climatic effects on breeding and morphology: evidence for climatic plasticity. J Anim Ecol 69:395-403
Pulido F (2007) Phenotypic changes in spring arrival: evolution, phenotypic plasticity, effects of weather and condition. Clim Res 35:5-23

Pulido F, Berthold P (2004) Microevolutionary response to climate change. Adv Ecol Res 35:151-183

Robinson RA, Learmonth JA, Hutson AM, Macleod CD and others (2005) Climate change and migratory species. BTO Research Report No. 414, Defra, London

Rodríguez-Teijeiro JD, Gordo O, Puigcerver M, Gallego S, Vinyoles D, Ferrer X (2005) African climate warming advances spring arrival of the common quail Coturnix coturnix. Ardeola 52:159-162

Root TL, Price JT, Hall KR, Schneider SH, Rosenzweig C, Pounds JA (2003) Fingerprints of global warming on wild animals and plants. Nature 421:57-60

Rosenthal R (1991) Meta-analytic procedures for social research. Sage Publications, London

Rubolini D, Spina F, Saino N (2005) Correlates of timing of spring migration in birds: a comparative study of transSaharan migrants. Biol J Linn Soc 85:199-210

Rubolini D, Møller AP, Rainio K, Lehikoinen E (2007a) Intraspecific consistency and geographic variability in temporal trends of spring migration phenology among European bird species. Clim Res 35:135-146

Rubolini D, Ambrosini R, Caffi M, Brichetti P, Armiraglio S, Saino N (2007b) Long-term trends in first arrival and first egg laying dates of some migrant and resident bird species in northern Italy. Int J Biometeorol 51:553-563

Saino N, Ambrosini R (2007) Climatic connectivity between Africa and Europe may serve as a basis for phenotypic adjustment of migration schedules of trans-Saharan migratory birds. Glob Change Biol (in press), doi: 10.1111/ j.1365-2486.2007.01488.x

Saino N, Szép T, Romano M, Rubolini D, Møller AP (2004) Ecological conditions during winter predict arrival date at the breeding grounds in a trans-Saharan migratory bird. Ecol Lett 7:21-25

Schlichting CD, Pigliucci M (1998) Phenotypic evolution: a reaction norm perspective. Sinauer, Sunderland

Schwartz MD, Ahas R, Aasa A (2006) Onset of spring starting earlier across the Northern Hemisphere. Glob Change Biol 12:343-351

Schwilch R, Mantovani R, Spina F, Jenni L (2001) Nectar consumption of warblers after long-distance flights during spring migration. Ibis 143:24-32

Sokolov LV, Markovets MY, Shapoval AP, Morozov YG (1998) Long-term trends in the timing of spring migration of passerines on the Courish Spit of the Baltic Sea. Avian Ecol Behav 1:1-21

Sparks TH, Mason CF (2001) Dates of arrivals and departures of spring migrants taken from Essex Bird Reports 1950-1998. Essex Bird Rep 1999:154-164

Sparks TH, Tryjanowski P (2007) Patterns of spring arrival dates differ in two hirundines. Clim Res 35:159-164

Sparks TH, Roberts DR, Crick HQP (2001) What is the value of first arrival dates of spring migrants in phenology? Avian Ecol Behav 7:75-85

Sparks TH, Bairlein F, Bojarinova JG, Hüppop H and others (2005) Examining the total arrival distribution of migratory birds. Glob Change Biol 11:22-30

Spiegelhalter D, Thomas A, Best N, Lunn D (2003) WinBUGS user manual, Version 1.4. Medical Research Council Biostatistics Unit, Cambridge

Spina F, Massi A, Montemaggiori A, Baccetti N (1993) Spring migration across central Mediterranean: general results from the 'Progetto Piccole Isole'. Vogelwarte 37(Suppl): $1-94$ 
Spina F, Piacentini D, Montemaggiori A (2006) Bird migration across the Mediterranean: Capri within the Progetto Piccole Isole. Ornis Svec 16:20-26

Stoate C, Moreby SJ (1995) Premigratory diet of transSaharan migrant passerines in the western Sahel. Bird Study 42:101-106

Szép T (1995) Relationship between West African rainfall and the survival of central European sand martins Riparia riparia. Ibis 137:162-168

Tryjanowski P, Kuzniak S, Sparks TH (2002) Earlier arrival of

Submitted: April 6, 2007; Accepted: October 30, 2007 some farmland migrants in western Poland. Ibis 144:62-68 Visbeck MH, Hurrel JW, Polvani L, Cullen HM (2001) The North Atlantic Oscillation: past, present and future. Proc Natl Acad Sci USA 98:12876-12877

Wellens J (1997) Rangeland vegetation dynamics and moisture availability in Tunisia: an investigation using satellite and meteorological data. J Biogeogr 24:845-855

Zalakevicius M, Bartkeviciene G, Raudonikis L, Janulaitis J (2006) Spring arrival response to climate change in birds: a case study from eastern Europe. J Ornithol 147:326-343

Proofs received from author(s): December 28, 2007 